\title{
Search for Energetic-Charged-Particle Emission from Deuterated Ti and Pd Foils
}

\author{
P. B. Price, S. W. Barwick, and W. T. Williams \\ Physics Department, University of California, Berkeley, California 94720 \\ J. D. Porter \\ Department of Chemistry, University of California, Berkeley and Lawrence Berkeley Laboratory, Berkeley, California 94720 \\ (Received 17 July 1989)
}

\begin{abstract}
Searching for evidence of "cold" nuclear fusion in deuterium-loaded Ti and Pd foils with plastic track detectors, we detected the emission of $\alpha$ particles from trace-heavy-element decay, but found no evidence of $d d$ fusion. Cycling $\mathrm{TiD}_{2}$ and $\mathrm{PdD}>0.4$, in high-pressure $\mathrm{D}_{2}$ cells between 1 and 15 bars and 77 and $300 \mathrm{~K}$, gave an upper bound of $0.7 \mathrm{~cm}^{-3} \mathrm{~s}^{-1}$ for the mean rate of $d d \rightarrow{ }^{3} \mathrm{He}+n$ fusion. For electrolytically deuterated $\mathrm{PdD}_{0.8}$ our upper bound is $0.0018 \mathrm{~cm}^{-3} \mathrm{~s}^{-1}$ for the mean rate of $d d \rightarrow p+t$. This is $\sim 1.5 \times 10^{6}$ and 180 times lower than "cold"-fusion rates reported by Fleischmann, Pons, and Hawkins and Jones et al., respectively.
\end{abstract}

PACS numbers: $25.45 .-\mathrm{z}, 62.50 .+\mathrm{p}, 82.45 .+\mathrm{z}$

Our work was motivated by recent reports ${ }^{1-6}$ of neutron emission from deuterated palladium and titanium. Those results have been interpreted as positive evidence for "cold" fusion of deuterons in these materials. To complement those experiments, we have searched for the recoiling charged particles which would also be produced by "cold" $d d$-fusion reactions.

Two types of experiments have yielded positive evidence of excess neutrons in nearby detectors. In the first, electrolysis of heavy-water electrolyte solutions is used to load Pd or $\mathrm{Ti}$ with deuterium by diffusion. From the neutron flux $\left(\mathrm{BF}_{3}\right.$ detector) reported by Fleischmann, Pons, and Hawkins, ${ }^{1}$ we calculate a specific rate for the neutron-producing $d d$-fusion channel in their $\operatorname{PdD}_{x}$ of $2700 \mathrm{~cm}^{-3} \mathrm{~s}^{-1}$. From the results of Jones et al., ${ }^{2}$ we calculate $0.33 \mathrm{~cm}^{-3} \mathrm{~s}^{-1}$ for the neutron channel based upon their observations of $2.5-\mathrm{MeV}$ neutrons in scintillation detectors near their $\mathrm{PdD}_{x}$ and $\mathrm{TiD}_{2}$ cathodes. Wolf et al. ${ }^{3}$ report neutron-source strengths of $0.8 \mathrm{~s}^{-1}$ for $\operatorname{PdD}_{x}$ cathodes of unspecified volume.

In the second type of experiment, high-pressure $\mathrm{D}_{2}$ gas is used to drive deuterons into $\mathrm{Ti}$ and Pd samples, which are then subjected to thermal and/or pressure cycling. De Ninno et al. ${ }^{4}$ detected bursts of neutrons using a $\mathbf{B F}_{3}$ counter during such sample cycling. Average source strengths during two separate episodes of activity were 20 and 260 neutrons $/ \mathrm{cm}^{3} \mathrm{~s}$. Ricci ${ }^{5}$ reported a source strength of $10^{6}$ neutrons $/ \mathrm{cm}^{3} \mathrm{~s}$ for one 10 -min episode. Menlove et al., ${ }^{6}$ using ${ }^{3} \mathrm{He}$ neutron detectors, reported infrequent, low-level $(\sim 100)$ neutron bursts and random emission levels between 0.001 and 0.04 neutrons $/ \mathrm{cm}^{3} \mathrm{~s}$ for sample mixtures containing $\mathrm{Ti}, \mathrm{Pd}, \mathrm{V}$, and $\mathrm{Sn}$.

In our experiments, we used CR-39 plastic film (Track Analysis Systems Inc., Bristol, United Kingdom) to detect energetic charged particles. CR-39 detects products arising from both conventional fusion channels: $\quad d+d \rightarrow p(3.02 \mathrm{MeV})+t(1.01 \mathrm{MeV}), \quad$ and $d+d \rightarrow{ }^{3} \mathrm{He}(0.82 \mathrm{MeV})+n(2.45 \mathrm{MeV})$. Damage tracks produced in CR-39 by ionizing particles are chemically etched $\left(6.25 \mathrm{~mol} \mathrm{NaOH}, 70^{\circ} \mathrm{C}\right)$ at a rate
$v_{T}>v_{G}$, where $v_{G}$ is the etch rate of the undamaged plastic. The resulting conical etchpits of cone angle $\Theta=\operatorname{arccsc}(s)$, where $s=v_{T} / v_{G}$, are identified and counted using optical-scanning methods. A particle's velocity $\beta c$ and charge $Z$ can be determined from its range $R$ and from $s$, which is a function of the ratio $(Z / \beta)$ (Ref. 7). Detection efficiency is $100 \%$ for charged particles, including protons, ${ }^{8}$ of energy $\geq 0.2 \mathrm{MeV}$ under ambient laboratory conditions.

In the present application, plastic-track detectors such as CR-39 offer several advantages over solid-state silicon-surface-barrier (SSB) detectors like those used by Ziegler et al.: ${ }^{9}$ (a) Electronic noise in SSB's limits particle detection to energies $>1 \mathrm{MeV}$ at low count rates. (b) SSB background counts between 1 and $3 \mathrm{MeV}$, $\sim 2.5 \mathrm{~cm}^{-2} \mathrm{~d}^{-1}$, are $>25 \times$ the integral background rate in CR-39. (c) Burst emissions of particles may not be detected by SSB's because of their finite response time ( $>5 \mu \mathrm{s})$ and limited energy window (1-8 MeV). (d) CR-39 determines particle charge, energy, location, and propagation direction, whereas single-element SSB's simply measure the integral energy deposited in the active volume of the detector within its response time. (The ranges of the protons are long enough that a twoelement silicon-particle telescope could be used to identify both charge and energy.)

There are three types of charged-particle backgrounds in CR-39 which are relevant to the present experiments. Between the time it is made and the time it is used, CR39 accumulates cosmic-ray spallation tracks and $\alpha$-decay tracks due to airborne radon. In our laboratory, the rate of production of detectable spallation recoil tracks is $\sim 1$ $\mathrm{cm}^{-2} \mathrm{yr}^{-1}$, and radon $\alpha$ tracks accumulate at a rate $\sim 1$ $\mathrm{cm}^{-2} \mathrm{~d}^{-1}$ while the film is exposed to open air. We were able to reduce these two sources of background to an accumulation rate of $<0.1 \mathrm{~cm}^{-2} \mathrm{~d}^{-1}$ by preetching the CR-39 for $8 \mathrm{~h}$ and locating existing tracks before starting the present experiments, and by protecting the CR-39 from airborne radon during the experiments.

The third source of background tracks is $\alpha$-emitting 
nuclides, predominantly the ${ }^{238} \mathrm{U}$ and ${ }^{232} \mathrm{Th}$ series, present as impurities in the Pd and $\mathrm{Ti}$ at ppm levels. $\alpha$ particles emerge from the surfaces of the Pd and Ti foils with a continuous distribution of energies, from 0 to 8.8 $\mathrm{MeV}$ in this case, because their ranges are less than the thickness of the foils. In a control experiment, we determined the $\alpha$-track production rate of our Pd and Ti foils due to this source by exposing them to CR-39 for $41 \mathrm{~d}$. Etching and analysis above yielded a production rate for $\geq 0.2-\mathrm{MeV} \alpha$ tracks of $\sim 5 \mathrm{~cm}^{-2} \mathrm{~d}^{-1}$ for the Pd foil and $\sim 1 \mathrm{~cm}^{-2} \mathrm{~d}^{-1}$ for the Ti foil. Note that $\alpha$ tracks do not interfere with a search for recoiling protons or tritons in CR-39, but those with lowest energy do place constraints on the determination of ${ }^{3} \mathrm{He}$ production rates.

Figure 1 shows the results of a calibration of the CR39 film as well as the data for the two experiments discussed below. The dashed curve through the points labeled "alphas" was obtained by irradiating CR-39 with $\alpha$ particles, slowed to various energies, from a ${ }^{252} \mathrm{Cf}$ source. The curves labeled "tritons" and "protons" were scaled from the $\alpha$-particle curve using a restrictedenergy-loss model of track formation. ${ }^{7}$ The proton curve is quantitatively similar to that obtained for CR-39 neutron spectrometers whose basis of operation is the detection of recoiling protons. ${ }^{8}$

Assuming that particles are emitted isotropically and uniformly throughout the samples, then the product of detection efficiency and effective source thickness, $\langle\eta H\rangle$, can be calculated by integrating over emission zenith angle $\theta$ and depth $z$ measured from the CR-39 into the source:

$$
\langle\eta H\rangle=\frac{1}{2} \int_{0}^{z_{\max }} \int_{0}^{\Theta_{\max }} \sin \Theta d \Theta d z,
$$

where $\boldsymbol{\Theta}_{\max }$ is the smaller of $\boldsymbol{\Theta}_{\max }=\arccos \left(z / z_{\max }\right)$ or $\Theta_{\max }-\arccos \left(v_{G} / v_{T}\right)$ and $z_{\max }$ is the smaller of $z_{\max }$

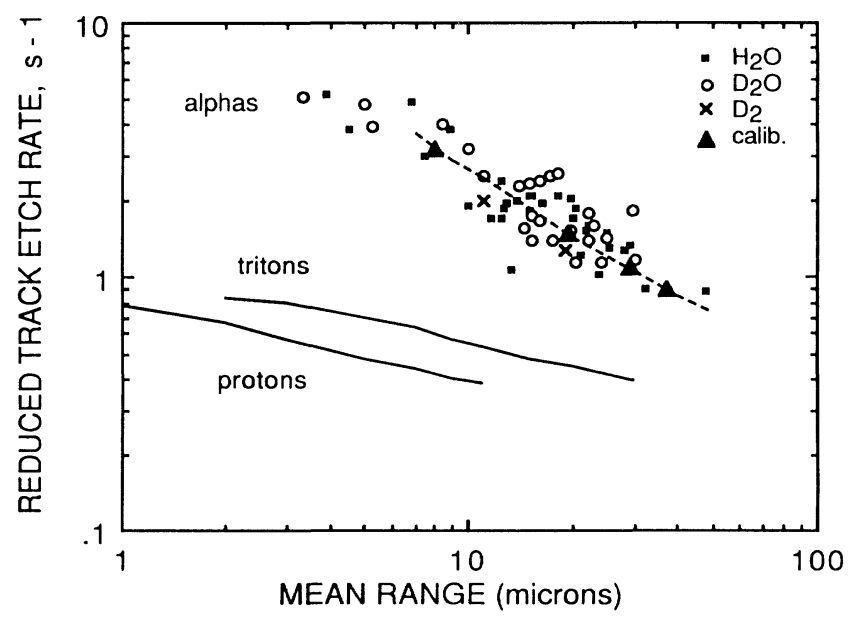

FIG. 1. Energetic particles detected by CR-39 film next to Pd foils: $\square$, electrolysis cell, $\mathrm{H}_{2} \mathrm{O}, 1 \mathrm{~mol} \mathrm{LiOH}$; O, electrolysis cell, $\mathrm{D}_{2} \mathrm{O}, 1 \mathrm{~mol}$ LiOD; $\times$, high-pressure $\mathrm{D}_{2}$ gas cell; $\Delta$, calibration with ${ }^{4} \mathrm{He}$ particles from ${ }^{252} \mathrm{Cf}$. $-d_{s}$, where $d_{s}$ is the sample thickness, or $z_{\max }$ $=(R-\delta R)-\Sigma d_{i} . R$ is the particle's range in the material, $\delta R$ is the minimum range needed for detection in the CR-39, and $\Sigma d_{i}$ is the sum of density-corrected thicknesses of all materials between the sample and CR39. The $d d$-fusion products are calculated to have the following ranges: in $\operatorname{PdD}_{0.8}, R(p)=33 \mu \mathrm{m}, R(t)=4.6$ $\mu \mathrm{m}$, and $R\left({ }^{3} \mathrm{He}\right)=1.3 \mu \mathrm{m}$; in $\mathrm{TiD}_{2}, R(p)=65 \mu \mathrm{m}$, $R(t)=6.5 \mu \mathrm{m}$, and $R\left({ }^{3} \mathrm{He}\right)=2.2 \mu \mathrm{m}$. As an example, for $0.82-\mathrm{MeV}{ }^{3} \mathrm{He}$ produced from $d d$ fusion and detected in CR-39, $\arccos \left(v_{G} / v_{T}\right) \sim 80^{\circ},\langle\eta H\rangle \sim 0.5 \mu \mathrm{m}$ in $\mathrm{PdD}_{0.4}$ and $\langle\eta H\rangle \sim 0.8 \mu \mathrm{m}$ in $\mathrm{TiD}_{2}$.

For our first experiment we cleaned a $0.1-\mathrm{mm}$-thick Ti foil (purity $>99.6 \%$ ) and a $0.23-\mathrm{mm}$-thick Pd foil (unknown purity) using aqua regia. After heating the foils to $550^{\circ} \mathrm{C}$ for $3 \mathrm{~h}$ in $\mathrm{D}_{2}$ gas at 1 bar they were allowed to cool in $\mathrm{D}_{2}$ to room temperature overnight. The diffusion coefficient for $\mathrm{D}$ in $\mathrm{Pd}$ at room temperature is $5 \times 10^{-7}$ $\mathrm{cm}^{2} \mathrm{~s}^{-1}$ (Ref. 10), high enough to fill the foil in a few hours, but temperatures $-500^{\circ} \mathrm{C}$ are required to achieve the same diffusion coefficient in Ti (Ref. 11). Final stoichiometries of the deuterated foils were determined by weight gain to be $\mathrm{TiD}_{2}$ and $\mathrm{PdD}>0.4$, the value for Pd being a lower bound because of possible loss of deuterium during handling.

The deuterated foils were then clamped against CR-39 sheets (contact area $2 \mathrm{~cm}^{2}$ for each sample) and put inside a stainless-steel pressure cell attached to a source of $D_{2}$ gas. After evacuating the cell using a roughing pump, we loaded $\mathrm{D}_{2}$ gas to a pressure of 15 bars and immersed the cell in liquid nitrogen for $1 \mathrm{~h}$ to allow sufficient time to cool the chamber, and then removed it from the liquid nitrogen, allowing it to warm to $20^{\circ} \mathrm{C}$ in about $2 \mathrm{~h}$. The cooling and warming cycle was repeated two more times. Prior to the last warming we removed the $D_{2}$ gas from the chamber with a roughing pump. The entire experiment lasted about $9 \mathrm{~h}$, after which we etched the CR-39 films for $1.7 \mathrm{~h}$ and searched the regions that had been in contact with the Pd and $\mathrm{Ti}$ foils for tracks produced since the preexisting ones were located.

Two tracks of particles with $Z=2$ came from the $P d$ (labeled $x$ in Fig. 1), and no tracks came from the Ti. We calibrated the response of CR-39 in the highpressure cell at 15 bars and $77 \mathrm{~K}$ using $\alpha$ particles from ${ }^{238} \mathrm{U}$ decay. We found that the sensitivity to an isotropic flux of particles with $Z=2$ inside the cell at $77 \mathrm{~K}$ was $\sim 80 \%$ of that at $20^{\circ} \mathrm{C}$ and 1 bar. The energies of both $Z=2$ particles from the deuterated Pd foil were too high to be due to $0.82-\mathrm{MeV}{ }^{3} \mathrm{He}$. The track production rate is consistent with the $\alpha$-particle emission rate for the $\mathbf{P d}$ foil determined in the control experiment. This null result was converted into an upper limit for the rate of the $d d \rightarrow{ }^{3} \mathrm{He}+n$ channel using Eq. (1), and is compared in Table I with the $d d$-fusion rates inferred from the neutron fluxes reported by De Ninno et al., Ricci, and Menlove et al. Lacking a source of particles with $Z=1$ for a 
TABLE I. "Cold"-fusion rates inferred from measurements of energetic particles.

\begin{tabular}{cccc}
\hline \hline & Duration & $\begin{array}{c}\text { Particle } \\
(\text { detector })\end{array}$ & $\begin{array}{c}\text { Fusion rate } \\
\left(\mathrm{cm}^{-3} \mathrm{~s}^{-1}\right)^{\mathrm{a}}\end{array}$ \\
\hline
\end{tabular}

Electrolysis experiments

Fleischmann, Pons, and Hawkins (Ref. 1) Jones et al. (Ref. 2) Wolf et al. (Ref. 3) Ziegler et al. (Ref. 9) This work

$\begin{array}{lrll}\mathrm{PdD}_{x} & 50 & \text { Neutrons }\left(\mathrm{FB}_{3}\right) & 2700 \\ \mathrm{TiD}_{2}(\# 6) & 8 & \text { Neutrons (scint.) } & 0.33 \\ \mathrm{PdD}_{x} & 1-2 & \text { Neutrons (NE213) } & \left(0.8 / V_{\mathbf{P d}}\right) \\ \mathrm{PdD}_{>0.6} & 250 & \text { Protons (SSB) } & <0.028 \\ \mathrm{PdD}_{0.8} & 307 & \text { Protons }(\mathrm{CR}-39) & <0.0018 \\ \mathrm{PdD}_{0.8} & 307 & \text { Tritons }(\mathrm{CR}-39) & <0.011\end{array}$

High-pressure $D_{2}$ gas experiments

\begin{tabular}{lllll} 
Menlove et al. (Ref. 6) & “Ti-1" & 18 & Neutrons $\left({ }^{3} \mathrm{He}\right)$ & $0.001-0.04$ \\
De Ninno et al. (Ref. 4) & $\mathrm{TiD}_{x}$ & $13^{\mathrm{b}}$ & Neutrons $\left(\mathrm{BF}_{3}\right)$ & $\sim 20$ \\
& $\mathrm{TiD}_{x}$ & $40^{\mathrm{b}}$ & Neutrons $\left(\mathrm{BF}_{3}\right)$ & $\sim 260$ \\
Ricci (Ref. 5) & $\mathrm{PdD}_{x}$ & $0.17^{\mathrm{b}}$ & Neutrons & Up to $10^{6}$ \\
This work & $\mathrm{TiD}_{2}$ & 9 & ${ }^{3} \mathrm{He}(\mathrm{CR}-39)$ & $<0.73$ \\
& $\mathrm{PdD}_{>0.4}$ & 9 & ${ }^{3} \mathrm{He}(\mathrm{Cr}-39)$ & $<2.6$ \\
\hline \hline
\end{tabular}

a To convert to fusions per $d d$ pair per second: For $\operatorname{TiD}_{2}, 1 \mathrm{~cm}{ }^{-3} \mathrm{~s}^{-1}=4.72 \times 10^{22}(d d)^{-1} \mathrm{~s}^{-1}$. For $\mathrm{PdD}_{x}, 1 \mathrm{~cm}^{-3} \mathrm{~s}^{-1}=\left[2 x /(0.3925+0.0165 x)^{3}\right] \times 10^{21}(d d)^{-1} \mathrm{~s}^{-1}$.

$\mathrm{b}$ Period during which excess neutrons were detected.

calibration inside the high-pressure cell, we report results only for the $n+{ }^{3} \mathrm{He}$ product channel.

Figure 2 shows an "exploded" view of the symmetric electrochemical cells used in our second experiment. Both cathodes were cut from the same piece of $25-\mu \mathrm{m}$ thick Pd sheet (99.9\%), and had a 100-nm Au diffusion barrier evaporated on the side which faced the CR-39. The cells were operated in electrical series using a single-current source (Keithley 220). Viton $O$ rings defined $1.26-\mathrm{cm}^{2}$ active electrode areas. Solutions were prepared by reacting degreased, isopropanol-etched $\mathrm{Li}$ under nitrogen with either $18-\mathrm{M} \Omega \mathrm{cm} \mathrm{H}_{2} \mathrm{O}$ [Milli-Q Plus purified, Anal. $0.014 \% \mathrm{D},<2$ tritium decays/ (min ml)] to form $1.00 \mathrm{~mol} \mathrm{LiOH,} \mathrm{or} \mathrm{with} \mathrm{D}_{2} \mathrm{O}$ [Cambridge Isotopes Laboratories, Lot No. F7962, Anal.

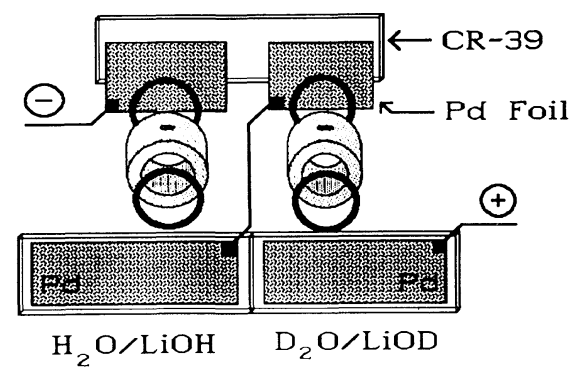

FIG. 2. "Exploded" schematic of the identical twin electrochemical cells. Cell bodies were $1.00-\mathrm{cm}$ lengths of Plexiglas tubing with a 2-mm-fill/vent hole and grooves machined for the Viton $\mathrm{O}$ rings. Anodes were $2-\mu \mathrm{m} e$-beam evaporated $\mathrm{Pd}$ on 100-nm Au on microscope slides.
$0.13 \% \mathrm{H}, 17.9$ tritium $\operatorname{decays} /(\mathrm{min} \mathrm{ml})]$ to form 1.00 mol LiOD.

The electrodes were presaturated with either $\mathbf{H}$ or $\mathrm{D}$ by constant-current electrolysis at $10 \mathrm{~mA} \mathrm{~cm}^{-2}$ for $12 \mathrm{~h}$. Coulometry during the presaturation period indicated initial electrode stoichiometries of $\mathrm{PdH}_{0.65}$ and $\mathrm{PdD}_{0.74}$ at the point of first gas bubble formation. Electrolysis was performed at $1.00 \mathrm{~mA} \mathrm{~cm}^{-2}$ for $13 \mathrm{~d}$. Steady-state cell operating voltages (includes $I R$-drop component plus kinetic overpotential) were $2.77 \mathrm{~V}\left(\mathrm{H}_{2} \mathrm{O}\right)$ and $2.96 \mathrm{~V}$ $\left(\mathrm{D}_{2} \mathrm{O}\right)$. Cathode stoichiometries were determined by mass change to be $\mathrm{Pd}(\mathrm{H}, \mathrm{D})_{0.8}$, a value consistent with in situ extended $\mathrm{x}$-ray-absorption fine-structure spectroscopy measurements of Pd-foil cathodes. ${ }^{12}$

After the run we etched the CR-39 for $8 \mathrm{~h}$ and searched for new tracks in the circular areas that had been in contact with the cathodes. We found 73 tracks at the light-water location and 65 tracks in the heavywater location; all tracks were due to particles with $Z=2$. The data are shown in Fig. 1. The track production rates agree at the $1 \sigma$ level and are consistent with the $\alpha$-particle emission rate for the native Pd foil discussed above. There were no tracks due to protons with $0.2 \mathrm{MeV} \leq E \leq 3 \mathrm{MeV}$ or tritons with $0.2 \mathrm{MeV} \leq E \leq 1$ MeV.

For 3-MeV protons from $d d$ fusion, $\arccos \left(v_{G} / v_{T}\right)$ $\sim 45^{\circ}$ in CR-39, and Eq. (1) gives $\langle\eta H\rangle=3.9 \mu \mathrm{m}$ for a 26.3- $\mu$ m-thick PdD $_{0.8}$ source. Similarly, for $1-\mathrm{MeV}$ tritons with $\arccos \left(v_{G} / v_{T}\right) \sim 60^{\circ}$, Eq. (1) gives $\langle\eta H\rangle=0.63$ $\mu \mathrm{m}$ for a $26.3-\mu \mathrm{m}$-thick $\mathrm{PdD}_{0.8}$ source. Table I lists our two upper limits on the $d d \rightarrow p+t$ channel. We com- 
pare this limit with the result of Ziegler et al. ${ }^{9}$ as follows: Using Eq. (1) we get $=3.1 \mu \mathrm{m}$ for their conditions (Expt. 1) of 1-3-MeV protons, 25- $\mu \mathrm{m}$-thick Pd cathode, $1.76-\mu \mathrm{m}$-thick gold diffusion barrier, and 2-mm air gap. From their observed count rate of 40 per $205 \mathrm{~h}$ we calculate the limiting fusion rate listed in Table I. The background rate in their experiments was consistent with the rate we found for $\alpha$ emission from radioactive impurities in our $\mathrm{Pd}$ foil. The reasons why our limit on the $d d$ fusion rate is lower than that of Ziegler et al. are the following: we have no detectable background for protons, we used a thinner gold diffusion barrier, there was no air gap, and CR-39 has a lower minimum detectable particle energy than SSB's.

In conclusion, the only energetic charged particles we detected in both our experiments were $\alpha$ particles emitted from trace radioactive impurities in $\mathrm{Pd}$ and $\mathrm{Ti}$ at rates of a few particles per $\mathrm{cm}^{2}$ per $d$, independent of the deuterium content of the foils. Our upper limits on average $d d$ "cold"-fusion rates are far below those inferred from neutron detection in experiments involving either electrolytic $^{1,2}$ or high-pressure ${ }^{6}$ loading of $D_{2}$ into $P d$ or Ti. To rationalize our null results with claims of episodic "cold" $d d$ fusion, ${ }^{3-6}$ it would be necessary to argue that fusion at the average rate reported by Jones et al. ${ }^{2}$ occurred less than $\frac{1}{180}$ of the time during which our electrolytic cell was operating and that fusion at the rate reported by De Ninno et al. occurred less than $\frac{1}{400}$ of the time during which we cycled $\mathrm{TiD}_{2}$ in $\mathrm{D}_{2}$ gas. (Although there appears to be no suitable mechanism, one might in principle observe neutrons and not short-range charged particles if deuterium were somehow depleted in a sur- face skin without being depleted in the interior. Such an ad hoc explanation of our null results could not apply to our search for protons in electrolysis.) Our limits apply to any mechanism that produces energetic charged particles in deuterated $\mathbf{P d}$ or $\mathrm{Ti}$, such as the neutron-initiated chain reaction proposed by Jackson. ${ }^{13}$

This work was supported in part by NSF Grant No. PHY -8702763 and by the Director, Office of Energy Research of the U.S. Department of Energy under Contract No. DE-AC03-76SF00098.

${ }^{1}$ M. Fleischmann, S. Pons, and M. Hawkins, J. Electroanal. Chem. 261, 301 (1989).

${ }^{2}$ S. E. Jones et al., Nature (London) 338, 737 (1989).

${ }^{3} \mathrm{~K}$. L. Wolf et al., in Proceedings of the Workshop on Cold Fusion Phenomena, Santa Fe, New Mexico, 23-25 May 1989 (to be published).

${ }^{4}$ A. De Ninno et al., Nuovo Cimento 101A, 841 (1989).

${ }^{5}$ R. A. Ricci, in Proceedings of the Fusion Workshop, Varenna, Italy, 2-4 May 1989 (to be published).

${ }^{6} \mathrm{H}$. O. Menlove et al. (to be published).

${ }^{7}$ R. L. Fleischer, P. B. Price, and R. M. Walker, Nuclear Tracks in Solids (Univ. of California Press, Berkeley, 1975).

${ }^{8}$ T. W. Turner, D. L. Henshaw, and A. P. Fews, Nuclear Tracks Adiat. Meas. 8, 341 (1984).

${ }^{9}$ J. F. Ziegler et al., Phys. Rev. Lett. 62, 2929 (1989).

${ }^{10} \mathrm{~J}$. Voelkl et al., Z. Naturforsch. 26a, 922 (1971).

${ }^{11}$ R. J. Wasilewski and G. L. Kehl, Metallurgia 50, 225 (1954).

${ }^{12}$ R. Frahm et al., in Ref. 3.

${ }^{13}$ J. C. Jackson, Nature (London) 339, 345 (1989). 